\title{
Cathinonen in webshops
}

\section{Vrij verkrijgbare experimentele harddrugs}

\author{
Michiel Olijhoek · Willem Koert · Edwin van den Worm
}

Published online: 18 November 2020

(c) The Author(s) 2020

\begin{abstract}
Samenvatting Webwinkels die zich richten op Nederlandse consumenten van recreatieve drugs, verkopen een snelgroeiend assortiment van synthetische drugs die door hun experimentele karakter op dit moment legaal kunnen worden verkocht. In een verkennend onderzoek, dat zich beperkte tot de onder de stimulantia vallende cathinonen, werden in deze winkels 26 cathinonen aangetroffen. Van geen van deze middelen is de toxiciteit goed onderzocht. Een trendanalyse van de cathinonen die onlangs in dit circuit zijn gelanceerd doet vrezen dat de bedenkers van deze middelen, in hun streven om nieuwe drugs te produceren die de regelgeving ontwijken, waarschijnlijk onbedoeld steeds verslavender drugs op de markt brengen.
\end{abstract}

Trefwoorden cathinonen $\cdot$ webshops $\cdot$ NPS $\cdot$ designer drugs

\section{Cathinones in web shops \\ Freely available experimental hard drugs}

Abstract Web shops targeting Dutch consumers of
recreational drugs sell a fast-growing range of syn-
thetic drugs which can currently be legally sold due
to their experimental nature. In an exploratory study,
limited to the cathinones - a group of drugs with stim-
ulant biological effects - 26 cathinones were found

M. Olijhoek

Universiteit Utrecht, Utrecht, Nederland

W. Koert $(\bowtie)$

Dopingautoriteit, Capelle aan den IJssel, Nederland

w.koert@dopingautoriteit.nl

E. van den Worm

Utrechts Instituut voor Farmaceutische Wetenschappen

(UIPS), Universiteit Utrecht, Utrecht, Nederland in these stores. The toxicity of none of these agents has been properly studied. A trend analysis of the cathinones recently launched in this circuit suggested that the inventors of these drugs, in their quest to manufacture new drugs that avoid regulation, may introduce substances with an increasingly addictive potential.

Keywords Cathinones · Web shops · NPS · Designer drugs

\section{Cathinonen}

Cathinonen zijn synthetische drugs die vallen onder de groep van de new psychoactive substances (NPS). NPS staan ook bekend als legal highs, bath salts en designer drugs. Dit zijn allemaal containerbegippen voor meerdere groepen synthetische drugs, en een daarvan betreft de groep van de cathinonen. Cathinonen zijn afgeleid van cathinon, de belangrijkste bioactieve stof in de Noord-Afrikaanse plant khat of Catha edulis. In delen van Oost-Afrika en het Saudische schiereiland gebruikt de lokale bevolking khat als een recreatieve drug tijdens sociale gebeurtenissen [1].

Cathinon, dat vrijkomt door te kauwen op de bladeren van khat, heeft een milde stimulerende werking en veroorzaakt een gevoel van welbevinden. Cathinon is een natuurlijke stof, de overige cathinonen niet. Die zijn in laboratoria ontwikkeld door het cathinonmolecuul te modificeren en doen qua biologische werking, bijwerkingen, potentieel tot misbruik en metabolisering denken aan stoffen als amfetamine, cocaïne en MDMA. Er zijn daarnaast ook enkele cathinonen op de markt als receptplichtige medicijnen, zoals het antidepressivum en de eetlustremmer bupropion, maar de meeste synthetische cathinonen staan te boek als recreatieve drugs. 
Uit sociaalwetenschappelijk onderzoek blijkt dat synthetische cathinonen, net als andere groepen van NPS, in Europa aan populariteit winnen. Cathinonen zijn in buurlanden vooral populair onder tieners, studenten, LGBT'ers en bezoekers van dance-evenementen [2]. Vergeleken met het gebruik van drugs als MDMA en cocaïne is in ons land het gebruik van synthetische cathinonen nog beperkt, al maakt bijvoorbeeld het Antenne-onderzoek uit 2018 al melding van het experimentele gebruik van de cathinonen 4-MMC en 3-MMC in enkele netwerken van Amsterdamse jongeren [3].

Omdat het mondiale antidopingagentschap de meeste cathinonen als doping beschouwt, is het gebruik van deze stoffen vlak voor en tijdens wedstrijden door sporters verboden. De dopinglijst van het World Anti-Doping Agency noemt cathinon, mefedron, mexedron en alfa-PVP (prolintanon) bij naam, maar de lijst verbiedt daarnaast bijna alle bekende en onbekende chemische cathinonvarianten.

\section{Webwinkels}

Omdat wereldwijd cathinonen vaker zijn gaan opduiken bij dopingcontroles, besloot de Nederlandse Dopingautoriteit te inventariseren welke cathinonen in Nederland circuleren. Omdat we aanwijzingen hadden dat het ging om middelen die via webwinkels waren aangeschaft, onderzochten we in het eerste halfjaar van 2020 het aanbod van synthetische cathinonen door de online retail. We selecteerden een aantal webwinkels die op de eerste pagina van een Googlezoekopdracht tevoorschijn kwamen toen we zochten op 'research chemicals kopen'. Google kende onze fysieke locatie. In deze winkels inventariseerden we alle leverbare cathinonen. In totaal hebben we acht webwinkels onderzocht. Sommige winkels werden onderhouden door enkele van de grootste distributeurs van Nederland, terwijl andere zich internationaal op consumenten richtten. Deze winkels bleken buiten Nederland te liggen, en opereerden vanuit Centraal- en West-Europa.

In het assortiment van de onderzochte webwinkels vonden we 26 synthetische cathinonen, die te koop werden aangeboden in de vorm van poeders. De prijs varieerde van 9 tot 30 euro per gram; gemiddeld kostte een gram van een (synthetisch) cathinon 16 euro. Ter vergelijking: een gram amfetamine, MDMA en cocaïne in poedervorm kosten volgens het Drugs Informatie en Monitoring Systeem van het Trimbos-instituut respectievelijk 7, 20 en 50 euro.

In de periode van maart tot april 2020 moesten we vier nieuwe stoffen aan onze lijst toevoegen. Niet omdat we ze over het hoofd hadden gezien, maar omdat ze tijdens ons onderzoek op de markt waren geïntroduceerd. Deze innovatiedrift is volgens Europese cijfers typerend voor deze groep middelen. In 2008 kende het European Monitoring Centre for Drugs and Drug Addiction (EMCDDA) zes synthetische cathino- nen, maar in 2012 waren dat er al dertig. In 2014 en 2015 verschenen respectievelijk 31 en 26 nieuwe cathinonen op de markt. In 2016 en 2017 liep dit aantal terug tot respectievelijk veertien en twaalf [4].

\section{Koortsachtige innovatie}

Deze vernieuwing vloeit voort uit het kat-en-muisspel dat de bedenkers/producenten van cathinonen met autoriteiten spelen. Onder de huidige regelgeving kan de Nederlandse overheid de handel in stoffen als cathinonen alleen reguleren als deze worden genoemd in de Opiumwet. Die lijst wordt geregeld aangevuld, maar op het moment dat een drug op de lijst terechtkomt, staken de producenten en verkopers de handel. Nieuwe drugs nemen hun plaats in. In veel Europese landen is de situatie niet wezenlijk anders.

Een voorbeeld van een synthetische cathinon is 4-MMC (4-methylmethcathinon). 4-MMC heet ook wel mefedron of miauw-miauw. 4-MMC is een van de eerste synthetische cathinonen die in laboratoria zijn ontwikkeld. Nadat 4-MMC in 1929 voor de eerst was gesynthetiseerd, gebruikten Russische artsen het middel tot de jaren veertig van de vorige eeuw als antidepressivum. Nadat duidelijk was geworden dat 4-MMC aantrekkelijk was als een recreatieve drug, staakten de producenten de productie. Rond de eeuwwisseling verscheen 4-MMC op de internationale zwarte markt als een 'legaal alternatief' voor MDMA, maar tien jaar later deed het EMCDDA 4-MMC in de ban [5].

In 2012 plaatste Nederland 4-MMC op lijst I van de Opiumwet. 4-MMC verdween hierop uit de webwinkels. Desondanks wordt dit middel nog steeds in beperkte mate gebruikt, doordat consumenten deze drug via andere kanalen kunnen krijgen. De webwinkels vervingen 4-MMC door cathinonvarianten met een chemische structuur die leek op die van 4-MMC, zoals 4-FMC en 4-CMC. Bij deze twee stoffen is de 4-methylgroep van 4-MMC vervangen door respectievelijk een 4-fluor- of een 4-chloorgroep. De laatstgenoemde 4-chloor-analoog is op dit moment verkrijgbaar via Europese websites.

Andere cathinonen die na het verbod op 4-MMC opdoken, waren 2-MMC (2-methylmethcathinon) en 3-MMC (3-methylmethcathinon). Ook deze drugs zijn varianten van 4-MMC. Ze zijn opgebouwd uit dezelfde bouwstenen, maar verschillen van 4-MMC doordat de methylgroep vastzit aan een andere plaats van het methcathinonmolecuul. De huidige wetgeving beschouwt al deze varianten als verschillend van 4-MMC. Na het verbod op de verkoop van 4-MMC, kunnen webwinkels deze varianten nog gewoon verkopen. Dat verandert pas als de wetgever de regels verandert, en ook deze stoffen gaat noemen in een nogmaals - veranderde Opiumwet. 
Tabel 1 Een overzicht van de beschikbare literatuur over de biologische effecten van synthetische cathinonen in webwinkels. Onderzoeken gemarkeerd met een asterisk gebruiken een ander diermodel dan ratten of muizen

\begin{tabular}{|c|c|c|c|c|c|}
\hline Chemische verbinding & Prijs per gram & Humane onderzoeken & Dieronderzoeken & In vitro-onderzoeken & Vergelijkbaar met \\
\hline 3-MMC & $€ 8,82-30,00$ & - & {$[10]^{*}$} & [11-13] & Amfetamine [12] \\
\hline 3-MEC & $€ 15,00-20,00$ & - & - & - & \\
\hline 4-MEC & $€ 20,00$ & - & [14-18] & {$[13,19-23]$} & MDMA $[15,16,20-22]$ \\
\hline 3-CMC & $€ 9,95-20,00$ & - & - & - & \\
\hline 4-CMC & $€ 9,95-20,00$ & - & [24] & {$[20,25-27]$} & MDMA [24] \\
\hline $4-C D C$ & $€ 18,00$ & - & - & - & \\
\hline 3-CEC & $€ 8,82$ & - & - & - & \\
\hline 4-CEC & $€ 10,00$ & - & - & - & \\
\hline Mexedron & - & - & - & {$[20,28]$} & \\
\hline 4-FPD & $€ 11,00$ & - & - & - & \\
\hline NEP & $€ 15,00-22,99$ & - & - & - & \\
\hline Hexedron & - & - & - & - & \\
\hline HEXEN & $€ 11,00-22,50$ & - & - & [20] & \\
\hline NDH & $€ 22,99$ & - & - & - & \\
\hline HEP & $€ 11,00-15,00$ & - & - & - & \\
\hline $4-\mathrm{Cl}-\alpha-\mathrm{PVP}$ & $€ 15,00$ & - & - & - & \\
\hline$\alpha-\mathrm{PiHP}$ & $€ 15,00-17,50$ & - & - & - & \\
\hline$\alpha-\mathrm{PHP}$ & $€ 20,00$ & - & [29] & {$[20,30]$} & Cocaïne/Methamfetamine $[20,29]$ \\
\hline Dimethylon & $€ 10,00$ & - & [24] & - & Cocaïne [24] \\
\hline Butylon & $€ 10,00$ & - & {$[31-37]^{*}$} & {$[36,38-41]$} & MDMA [31, 36, 40, 41] \\
\hline Dibutylon & $€ 18,00$ & - & [24] & - & Cocaïne [24] \\
\hline Eutylon & $€ 11,00$ & - & - & - & \\
\hline Ephylon & $€ 18,00$ & - & {$[24,42,43]$} & [44] & Methamfetamine [24] \\
\hline N-ethylhexylon & - & - & - & - & \\
\hline MDPEP & $€ 20,00$ & - & - & - & \\
\hline$\alpha$-PCYP & $€ 20,00$ & - & - & - & \\
\hline
\end{tabular}

\section{Gezondheidsrisico's}

Het zal duidelijk zijn dat de vernieuwingsdrift van de cathinonenmarkt het voor wetgevers moeilijk maakt om greep te krijgen op deze markt. Daar komt nog bij dat de continue verandering van het aanbod van drugs, al of niet aangewakkerd door mediabelangstelling, de nieuwsgierigheid van potentiële consumenten prikkelt.

Weer een ander en onderbelicht probleem is dat de chemische creativiteit van deze markt ertoe heeft geleid dat er steeds obscuurder middelen op de markt komen. Van de 26 cathinonen die we in webwinkels hadden getraceerd, konden we in de online databank van PubMed geen enkel onderzoek naar de biologische effecten vinden dat was uitgevoerd met menselijke proefpersonen (zie tab. 1).

Van achttien cathinonen konden we geen enkel proefdieronderzoek vinden naar de biologische effecten. Van acht cathinonen (31\%) konden we dus wel enkele onderzoeken vinden, maar daarbij moeten we opmerken dat we van geen enkele cathinon een dieronderzoek konden vinden waarin de onderzoekers de toxiciteit van de bewuste stoffen systematisch hadden onderzocht.

Als we ook kijken naar in vitro-onderzoeken, verandert het beeld niet wezenlijk. Met de in vitro-onderzoeken meegerekend, hebben we over de tien van de 26 cathinonen (38\%) enige onderzoeken in handen die ons iets vertellen over de biologische effecten van deze middelen. Het gros van deze onderzoeken zegt iets over de psychoactieve eigenschappen, maar het beschikbare onderzoeksmateriaal laat ons in het ongewisse over mogelijke bijwerkingen. Cathinonen vallen, net als amfetamine, MDMA en cocaïne, onder de stimulantia. Misbruik van veel stimulantia kan leiden tot onder meer levertoxiciteit, toename van de bloeddruk en de hartslag, insomnie en hypomanie.

Hoe riskant de cathinonen die we aantroffen in webwinkels precies zijn, weten we dus niet. Dat is op zichzelf al zorgwekkend. Een analyse van de trends in dit circuit suggereert dat de bedenkers en produ- 


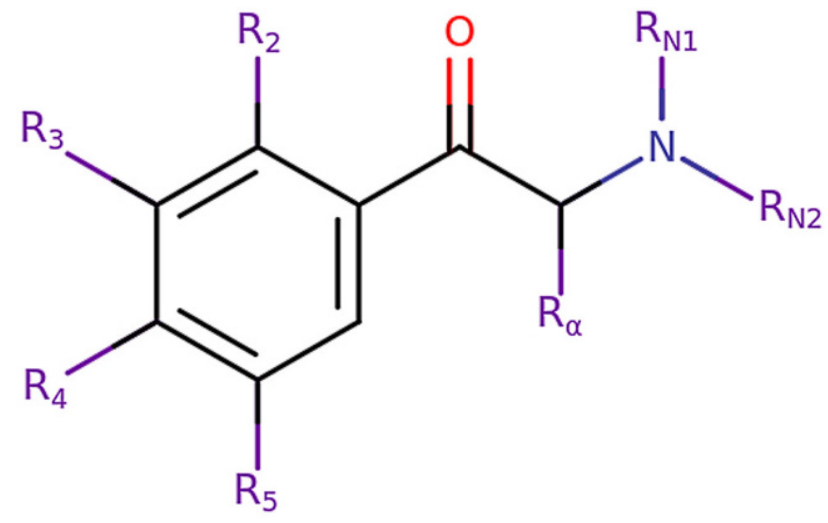

Figuur 1 De chemische structuur van synthetische cathinonen

centen van nieuwe cathinonen, in hun streven om verbodsbepaling voor te blijven, misschien een aantal stoffen op de markt hebben gebracht die een onvermoed sterke verslavende werking hebben.

\section{Psychofarmacologie}

De meeste cathinonen hebben grofweg een gecombineerde stimulerende en entactogene werking. Een stimulerende stof verdrijft vermoeidheid en honger, vergroot de alertheid en geeft een gevoel van controle en zelfververtrouwen. Een entactogene stof veroorzaakt een gevoel van emotionele verbondenheid en openheid. Hoe sterk de stimulerende of entactogene werking van een cathinon precies is, hangt af van zijn chemische structuur.

Cathinonen verhogen in de hersenen de activiteit van de neurotransmitters dopamine, noradrenaline en serotonine. Preciezer: cathinonen kunnen de concentratie van deze monoamines in de synaps verhogen door hun transport door het presynaptische membraan te stimuleren, hun afbraak te verminderen of hun heropname door monoamine-reuptake transporters af te remmen [6]. Dit werkingsmechanisme is niet wezenlijk anders dan dat van amfetamine, MDMA en cocaïne.

Fig. 1 laat zien op welke plaatsen chemici het cathinonmolecuul kunnen versleutelen. Ze kunnen groepen vastmaken aan de ringstructuur op de plaatsen R2, R3, R4 en R5. In de tweede plaats kunnen ze de alfa-zijketen R-alfa verlengen. De figuur laat de structuur zien van cathinon, en cathinon heeft een alfazijketen die uit slechts één methylgroep bestaat. In de derde plaats kunnen chemici ketens vastmaken bij de aminogroep van cathinon, aan RN1 en RN2. Bij cathinon zitten daar waterstofatomen, maar die kunnen worden vervangen.

Als we op een rijtje zetten welke nieuwkomers de EMCDDA in 2008 en 2012 heeft onderscheiden, en de nieuwe cathinonen die wij zelf in 2020 vonden, dan zien we twee trends. De eerste is dat de bedenkers van deze nieuwe middelen steeds vaker kiezen voor een variant met een verlengde alfa-zijketen, en dat die alfa-zijketen dus ook steeds langer wordt.

De tweede trend betreft het plakken van groepen aan de ringstructuur. Aanvankelijk lijken chemici vooral gekozen te hebben voor het substitueren van methylgroepen aan R3 en R4, later kiezen ze voor fluor- en weer later voor chlooratomen op deze plaatsen.

We zien vaak dat cathinonen met een verlengde alfa-zijketen ook ringsubstituties hebben. Een voorbeeld van zo'n cathinon die op dit moment in webwinkels ligt is MDPEP (3,4-methylenedioxypyrrolidinoheptafenon). Een mogelijk gezondheidsprobleem dat kleeft aan cathinonen met een verlengde alfa-zijketen is dat ze ten opzichte van het moedermolecuul in sterkere mate de heropname van dopamine afremmen [7]. Uit fundamenteel onderzoek komen aanwijzingen dat de dopaminerge werking van recreatieve drugs een factor van betekenis is in hun eventuele verslavende werking [8].

\section{Reden tot zorg}

De uitkomsten van ons verkennende onderzoek zijn niet geruststellend. Via webwinkels vinden obscure en experimentele drugs hun weg naar een groep overwegend jonge consumenten, zonder dat de overheid de verkopers van deze middelen een strobreed in de weg kan leggen. Een voorgestelde modernisering van de Opiumwet, die het mogelijk maakt om cathinonen als groep te verbieden, zal deze situatie mogelijk in gunstige zin veranderen. De vernieuwde wet zou het mogelijk maken om alle stoffen te verbieden met een 2-fenethylaminestructuur die het effect van verboden drugs kunnen imiteren [9]. Daaronder vallen ook de cathinonen.

Maar ook als de modernisering van de Opiumwet doorgang vindt, is het nog allerminst zeker of hierdoor ook het aanbod van obscure cathinonen, met mogelijk aanzienlijke negatieve gezondheidseffecten, zal verdwijnen. Hulpverleners, artsen en beleidsmakers hebben baat bij meer kennis en begrip over deze groep middelen.

Open Access This article is licensed under a Creative Commons Attribution 4.0 International License, which permits use, sharing, adaptation, distribution and reproduction in any medium or format, as long as you give appropriate credit to the original author(s) and the source, provide a link to the Creative Commons licence, and indicate if changes were made. The images or other third party material in this article are included in the article's Creative Commons licence, unless indicated otherwise in a credit line to the material. If material is not included in the article's Creative Commons licence and your intended use is not permitted by statutory regulation or exceeds the permitted use, you will need to obtain permission directly from the copyright holder. To view a copy of this licence, visit http://creativecommons.org/licenses/by/4.0/. 


\section{Literatuur}

1. Toennes SW, Harder S, Schramm M, Niess C, Kauert GF. Pharmacokinetics of cathinone, cathine and norephedrine after the chewing of khat leaves. Br J Clin Pharmacol. 2003;56(1):125-30.

2. Gilani F. Novel psychoactive substances: the rising wave of 'legal highs. Br J Gen Pract. 2016;66(642):8-9.

3. Korf DJ, Nabben T, Benschop A. Antenne 2018. Trends in alcohol, tabak en drugs bij jonge Amsterdammers. Amsterdam: Rozenberg Publishers; 2019.

4. Gonçalves JL, Alves VL, Aguiar J, Teixeira HM, Câmara JS. Synthetic cathinones: an evolving class of newpsychoactive substances. Crit RevToxicol. 2019;49(7):549-66.

5 . Kelly JP. Cathinone derivatives: a review of their chemistry, pharmacology and toxicology. Drug Test Anal. 2011;3(7-8):439-53.

6. Korpi ER, Hollander B den, Farooq U, et al. Mechanisms of action and persistent neuroplasticity by drugs of abuse. Pharmacol Rev. 2015;67(4):872-1004.

7. Glennon RA, Dukat M. Structure-activity relationships of synthetic cathinones. In: Geyer MA, Ellenbroek BA, Marsden CA, al, redactie. Current topics in behavioral Neurosciences. band 32. New York: Springer; 2016.

8. Chen W, Nong Z, Li Y, et al. Role of dopamine signaling in drug addiction. Curr Top Med Chem. 2017;17(21):2440-55.

9. Rijksoverheid. Wetsvoorstel Blokhuis en Grapperhaus plaatst groepen designerdrugs op lijst Ia van de Opiumwet. 2020. https://www.rijksoverheid.nl/ actueel/nieuws/2020/03/06/wetsvoorstel-blokhuis-engrapperhaus-plaatst-groepen-designerdrugs-op-lijst-iavan-de-opiumwet. Geraadpleegd op 16 november 2020.

10. Shimshoni JA, Britzi M, Sobol E, Willenz U, Nutt D, Edery N. 3-Methyl-methcathinone: pharmacokinetic profile evaluation in pigs in relation to pharmacodynamics. J Psychopharmacol. 2015;29(6):734-43.

11. Dias da Silva D, Ferreira B, Roque Bravo R, et al. The new psychoactive substance 3-methylmethcathinone (3-MMC or metaphedrone) induces oxidative stress, apoptosis, and autophagy in primary rat hepatocytes at human-relevant concentrations. Arch Toxicol. 2019;93(9):2617-34.

12. Luethi D, Kolaczynska KE, Docci L, Krähenbühl S, Hoener MC, Liechti ME. Pharmacological profile of mephedrone analogs and related new psychoactive substances. Neuropharmacology. 2018;134:4-12.

13. Zwartsen A, Olijhoek ME, Westerink RHS, Hondebrink L. Hazard characterization of synthetic cathinones using viability, monoamine reuptake, and neuronal activity assays. Front Neurosci. 2020;14:9.

14. Gatch MB, Rutledge MA, Forster MJ. Discriminative and locomotor effects of five synthetic cathinones in rats and mice. Psychopharmacology. 2015;232(7):1197-205.

15. Huskinson SL, Naylor JE, Townsend EA, Rowlett JK, Blough BE, Freeman KB. Self-administration and behavioral economics of second-generation synthetic cathinones in male rats. Psychopharmacology. 2017;234(4):589-98.

16. Naylor JE, Freeman KB, Blough BE, Woolverton WL, Huskinson SL. Discriminative-stimulus effects of second generation synthetic cathinones in methamphetamine-trained rats. DrugAlcohol Depend. 2015;149:280-4.

17. Peng X, Yi Q, Yizhi Z, et al. The effects of 4-methylethcathinone on conditioned place preference, locomotor sensitization, and anxiety-like behavior: a comparison with methamphetamine. Int J Neuropsychopharmacol. 2016;19(4):120.
18. Watterson LR, Olive MF. Synthetic cathinones and their rewarding and reinforcing effects in rodents. Adv Neurosci. 2014;2014:209875.

19. Araújo AM, Valente MJ, Carvalho M, etal. Raising awareness of new psychoactive substances: chemical analysis and in vitro toxicity screening of 'legal high' packages containing synthetic cathinones. Arch Toxicol. 2015;89(5):757-71.

20. Eshleman AJ, Wolfrum KM, Reed JF, et al. Structure-activity relationships of substituted cathinones, with transporter binding, uptake, and release. J Pharmacol Exp Ther. 2017;360(1):33-47.

21. Saha K, Partilla JS, Lehner KR, et al. 'Second-generation' mephedrone analogs, 4-MEC and 4-MePPP, differentially affect monoamine transporter function. Neuropsychopharmacology. 2015;40(6):1321-31.

22. Simmler LD, Buser TA, Donzelli M, et al. Pharmacological characterization of designer cathinones in vitro. $\mathrm{Br} J$ Pharmacol. 2013;168(2):458-70.

23. Valente MJ, Araújo AM, Lourdes Bastos M de, et al. Editor's highlight: characterization of hepatotoxicity mechanisms triggered by designer cathinone drugs ( $\beta$-keto amphetamines)-PubMed. Toxicol Sci. 2016;153(1):89-102.

24. Gatch MB, Dolan SB, Forster MJ. Locomotor activity and discriminative stimulus effects of five novel synthetic cathinone analogs in mice and rats. Drug Alcohol Depend. 2019;199:50-8.

25. Luethi D, Walter M, Zhou X, Rudin D, Krähenbühl S, Liechti ME. Para-halogenation affects monoamine transporter inhibition properties and hepatocellular toxicity of amphetamines and methcathinones. Front Pharmacol. 2019;10:438.

26. Zhou X, Bouitbir J, Liechti ME, Krähenbühl S, Mancuso RV. Hyperthermia increases neurotoxicity associated with novel methcathinones. Cells. 2020a;9(4):965.

27. Zhou X, Bouitbir J, Liechti ME, Krähenbühl S, Mancuso RV. Para-halogenation of amphetamine and methcathinone increases themitochondrial toxicityinundifferentiatedand differentiatedSH-SY5Ycells. IntJMolSci. 2020b;21(8):2841.

28. McLaughlin G, Morris N, Kavanagh PV, et al. Synthesis, characterization and monoamine transporter activity of the newpsychoactive substance mexedrone and its $\mathrm{N}$-methoxy positionalisomer, N-methoxymephedrone. DrugTestAnal. 2017;9(3):358-68.

29. Gatch MB, Dolan SB, Forster MJ. Locomotor activity and discriminative stimulus effects of a novel series of synthetic cathinone analogs in mice and rats. Psychopharmacology. 2017;234(8):1237-45.

30. Chen Y, Canal CE. Structure-activity relationship study of psychostimulant synthetic cathinones reveals nanomolar antagonist potency of $\alpha$-pyrrolidinohexiophenone at human muscarinic M2 receptors. ACS Chem Neurosci. 2020;11(6):960-8.

31. Dolan SB, Chen Z, Huang R, Gatch MB. 'Ecstasy' to addiction: mechanisms and reinforcing effects of three synthetic cathinone analogs of MDMA. Neuropharmacology. 2018;133:171-80.

32. Gatch MB, Taylor CM, Forster MJ. Locomotor stimulant and discriminative stimulus effects of 'bath salt' cathinones. Behav Pharmacol. 2013;24(0):437-47.

33. Grecco GG, Sprague JE. Impact of functional group modifications on designer phenethylamine-induced hyperthermia. Chem Res Toxicol. 2016;29(5):871-8.

34. Grecco GG, Kisor DF, Magura JS, Sprague JE. Impact of common clandestine structural modifications on synthetic cathinone 'bath salt' pharmacokinetics. Toxicol Appl Pharmacol. 2017;328:18-24. 
35. Grecco GG, Kisor DF, Sprague JE. Pharmacokinetic data of synthetic cathinones in female Sprague-Dawley rats. Data Brief. 2018;21:1045-50.

36. López-Arnau R, Martínez-ClementeJ, PubillD, Escubedo E, Camarasa J. Comparative neuropharmacology of three psychostimulant cathinone derivatives: butylone, mephedrone and methylone. BrJPharmacol. 2012;167(2):407-20.

37. Zsedényi CK, Zachar G, CsillagA,ÁdámÁ. Effect of synthetic cathinones: mephedrone, butylone and 3,4 methylenedioxypyrovalerone (MDPV) on social separation induced distress vocalization, vigilance and postural control of young domestic chicks. Neurosci Lett. 2014;580:88-93.

38. Eshleman AJ, Wolfrum KM, Hatfield MG, Johnson RA, Murphy KV, Janowsky A. Substituted methcathinones differ in transporter and receptor interactions. Biochem Pharmacol. 2013;85(12):1803-15.

39. Leong HS, Philp M, Simone M, Witting PK, Fu S. Synthetic cathinones induce cell death in dopaminergic SH-SY5Y cells via stimulating mitochondrial dysfunction. Int J Mol Sci. 2020;21(4):1370.
40. Saha K, Li Y, Holy M, et al. The synthetic cathinones, butylone and pentylone, are stimulants that act as dopamine transporter blockers but 5-HT transporter substrates. Psychopharmacology. 2019;236(3):953-62.

41. Simmler LD, Rickli A, Hoener MC, Liechti ME. Monoamine transporter and receptor interaction profiles of a new series of designer cathinones. Neuropharmacology. 2014;79:152-60.

42. Li J, Lin Z, Tao X, et al. Effects of N-ethylpentylone on locomotor activity and anxiety-like behavior in rats. Behav Pharmacol. 2019;30(6):500-5.

43. Lin Z, Chen Y, Li J, et al. Pharmacokinetics of N-ethylpentylone and its effect on increasing levels of dopamine and serotonin in the nucleus accumbens of conscious rats. AddictBiol. 2020;25(3):e12755.

44. Costa JL, Cunha KF, Lanaro R, Cunha RL, Walther HD, Baumann MH. Analytical quantification, intoxication case series, and pharmacological mechanism of action for N-ethylnorpentylone (N-ethylpentylone or ephylone). Drug Test Anal. 2019;11(3):461-71. 